PONENCIA - VIII Simposio Internacional de Estudios Generales

\title{
LA LECTURA Y LA ESCRITURA COMO MEDIACIÓN PEDAGÓGICA PARA LA FORMACIÓN INTEGRAL DE LOS ESTUDIANTES
}

\author{
Clara Inés Jaramillo Gaviria ${ }^{1}$, Edwin Francisco Forero García ${ }^{2}$, Adriana Cecilia Páez Pino ${ }^{3}$, \\ ${ }^{1,2}$ Universidad Santo Tomás, Colombia, clarajaramillo@usantotomas.edu.co, \\ edwinforero@,usantotomas.edu.co, ${ }^{3}$ Fundación Universitaria los Libertadores, Colombia, \\ adriana.paez@libertadores.edu.co.
}

El hombre es un animal hablador, porque capta, lee, elige el interior de las cosas, el más allá de su apariencia inmediata. Porque entiende y elige, es capaz de hablar y de razonar y de muchas otras actividades... La palabra es y será siempre el vehículo de la realidad. Sólo cuando existan las palabras, el hombre comprenderá su mundo y se experimentará como un ser situado en él. Santo Tomás de Aquino.

Si realmente pudiéramos comunicarnos, el compañerismo, la participación, la amistad y el amor crecerían más y más. Ése podría ser el camino. Tal vez, cuando nuestro diálogo alcance ese nivel de coherencia, podamos trascender la noción de que somos simplemente un grupo que trata de resolver los problemas sociales. Tal vez entonces pueda producirse una transformación en el individuo y en nuestra relación con el cosmos. Esta energía ha sido llamada «comunión», un tipo de participación a

la que los cristianos primitivos denominaban con el término griego koinonia, cuya raíz significa «participar», es decir, participar de la totalidad, formar parte de ella; no sólo del grupo sino de la totalidad.

David Bohm.

\section{Resumen:}

En el presente artículo se pretende reflexionar sobre las posibles soluciones al problema que se nos plantea en la academia al tratar de promover en nuestros estudiantes una actitud comunicativa que les

\footnotetext{
${ }^{1}$ Candidata a Doctora en Educación en Mediación Pedagógica de la Universidad de la Salle de Costa Rica, magister en Educación de la Universidad Santo Tomás de Colombia, Especialista en pedagogía de la comunicación y medios interactivos de la Universidad Distrital Francisco José de Caldas de Colombia, Licenciada en filosofía y letras de la Universidad Santo Tomás de Colombia y periodista de la Fundación Universitaria los Libertadores de Colombia. Ha trabajado como docente e investigadora en instituciones de educación media y superior y en la Vicerrectoría de Universidad Abierta y a Distancia (VUAD) de la Universidad Santo Tomás. Actualmente se desempeña como coordinadora de Lectoescritura y docente del Departamento de Humanidades y Formación Integral de la Universidad Santo Tomás de Colombia.

${ }^{2}$ Candidato a Doctor en Educación en Mediación Pedagógica de la Universidad de la Salle de Costa Rica, magister en Ingeniería Área Ingeniería Electrónica, Ingeniero Electricista, Coordinador (E) Maestría Ingeniería Electrónica Universidad Santo Tomás - Colombia, Docente Ingeniería Electrónica Universidad Santo Tomás - Colombia.

${ }^{3}$ Candidata a Doctora en Educación en Mediación Pedagógica de la Universidad de la Salle de Costa Rica. Ha ocupado cargos académicos Decana de Ingeniería Electrónica, Directora del Departamento de Ciencias Básicas, Directora de Laboratorios, de la Universidad Santo Tomás, Vicedecana de la Escuela de Ingenierías de la Universidad Sergio Arboleda, Presidenta de la Red de programas de Ingeniería Electrónica REDIE, con experiencia en procesos académicos y de gerencia universitaria, y de procesos formales para registros calificados, acreditación y creación de nuevos programas. Actualmente, se desempeña como Decana de Ingenierías de la Fundación Universitaria los Libertadores.
} 
permita establecer diálogos que responda a las necesidades comunes al ser humano y al entorno en que vivimos.

Palabras clave: educación, actitud comunicativa, lectura, escritura, formación integral.

La sociedad del conocimiento occidental, que se gestó a finales del Siglo XX con la globalización y se desarrolla en los inicios del Siglo XXI, se fundamenta en los avances de las tecnologías informáticas y el conocimiento. Estos avances han tejido redes de información y comunicación mediática casi instantánea a nivel mundial. Sin embargo, la información fluye de manera tan rápida y fragmentada que en la mayoría de los casos no permite la retroalimentación reflexiva de los receptores sino la respuesta inmediata de juicios y pareceres personales. Este fenómeno comunicativo conlleva a que las redes de información y comunicación se conviertan en una polifonía contrapuntística donde cada receptor mantiene y defiende su punto de vista y, aunque pueda guardar relación con las demás, no genera un diálogo que permita la emergencia de algo nuevo, creativo de manera conjunta. Por ello David Bohm afirma:

Cuando, por el contrario la única intención de los implicados es la de transmitir determinadas ideas o puntos de vista, como si se tratara de ítems de información, estarán inevitablemente condenados a fracasar porque, en tal caso, escucharán a los demás a través del filtro de sus propios pensamientos y tenderán a mantenerlos y a defenderlos, independientemente de su verdad y de su coherencia. $Y$ este tipo de comunicación terminará generando la confusión propia de los insolubles «problemas de comunicación» (Bohm, 1997, pág. 25).

Pero para no quedarnos en el desalentador panorama del diagnóstico se requiere reflexionar en las posibles soluciones al problema que se nos plantea, por ello desde la academia nos preguntamos: ¿cómo promover en nuestros estudiantes una actitud comunicativa que les permita establecer diálogos que responda a las necesidades comunes al ser humano y al entorno en que vivimos?

Con el objetivo de responder la preguntar anterior, proponemos el siguiente recorrido: en primer lugar, estableceremos la relación entre cultura y educación como elementos fundamentales para promover la actitud comunicativa que permite establecer diálogos que respondan a las necesidades comunes del ser humano y su entorno; en segundo lugar, explicitaremos la importancia de la lectura y la escritura en el proceso de aprendizaje; por 
último, relacionaremos las competencias comunicativas y la formación integral del profesional del Siglo XXI.

\section{La actitud comunicativa}

La comunicación es nuestro primer acto de vida, a través de ella recibimos las primeras nociones vitales y es nuestro primer contacto con el mundo; es la primera manifestación de nuestra afectividad y a la vez es el patrimonio del ser humano y la herencia de todos. El acto comunicativo está formado por una unidad lingüística, que tiene que ver con diferentes procesos cognitivos, éticos y estéticos. El conocimiento se construye usando el lenguaje que se tiene a disposición, de ahí la necesidad de desarrollar el lenguaje como una forma de apropiación del conocimiento.

Las aptitudes comunicativas se estimulan en tanto que el estudiante escucha, habla, lee y escribe sobre contextos y situaciones significativas para él, las incorpora a su pensamiento al reflexionar sobre ellas y comprenderlas, y luego, puede expresar apropiadamente el producto de esas reflexiones. En este sentido, la didáctica del lenguaje requiere propiciar espacios donde los estudiantes desarrollen habilidades lingüísticas que le permitan ampliar sus horizontes de sentido y desenvolverse en el mundo actual como estudiante y futuro profesional.

Si consideramos que la educación es el medio por el cual cada cultura y sociedad se constituye, desarrolla y evoluciona en sí misma; y que a su vez la persona es un proyecto que se construye a sí mismo, a través de su subjetividad cultural y socialmente a través de la intersubjetividad; podemos establecer que la educación es una mediación fundamental para promover en los jóvenes una actitud comunicativa que les permita establecer diálogos para asumir, de manera reflexiva y consiente, el papel protagónico de su momento histórico.

El educar se constituye en el proceso en el cual el niño o el adulto convive con otro y al convivir con el otro se transforma espontáneamente de manera que su modo de vivir se hace progresivamente más congruente con el del otro en el espacio de convivencia. El educar ocurre, por lo tanto, todo el tiempo; de manera recíproca, como una transformación estructural contingente a una historia en el convivir en el que resulta que las personas aprenden a vivir de una manera que se configura según el convivir de la comunidad donde viven. La educación como "sistema educacional" configura un mundo y los educandos confirman en su vivir el mundo que vivieron en su educación. Los educadores, a su vez, confirman el mundo que vivieron al ser educados en el educar (Maturana, 2001, pág. 18). 
Como primer paso para establecer un diálogo que responda a las necesidades comunes al ser humano y al entorno en que vivimos se requiere escuchar de manera adecuada a los otros, es decir, sin prejuicios para reflexionar, sopesar las semejanzas y diferencias, para comprender que nada permanece fijo, estático y controlado, que el universo entero se crea y recrea constantemente y que a esa realidad no escapa el devenir del hombre.

\begin{abstract}
Se trata, en principio, de conseguir que todo el mundo aprenda a escuchar y conocer las opiniones de los demás, porque el hecho de ignorarlas nos lleva a reaccionar de acuerdo con lo que suponemos al respecto, lo cual genera todo tipo de problemas. Porque, en tal caso, la otra persona se queda perpleja y se pregunta «¿pero qué dice?», lo cual le lleva, a su vez, a reaccionar basándose en sus propias creencias y no hace sino consolidar el círculo vicioso de la confusión. Es muy importante, pues, conocer cuáles son las creencias de los demás (Bohm, 1997, pág. 77).
\end{abstract}

Cuando en el proceso de aprendizaje experimentamos el escucharnos nos abrimos al diálogo y pasamos del enfrentamiento, dominio y control al compartir. Además, rompemos los bloqueos de lo que nos gusta y nos disgusta para entrar en el universo entramado de las relaciones entre las distintas asignaturas y la vida cotidiana de los aprendientes. Pero para ello se requiere un espacio de legítima presencia donde el respeto de sí mismo y el otro comulgan en el devenir relacional de la comunidad aprendiente. En este diálogo ya no se busca ganar, tener la razón sino preguntarse ¿bajo qué circunstancias lo dicho tiene validez?, pues no se trata de demostrar si lo dicho es correcto o incorrecto, sino en dar argumentos claros y coherentes o presentar pruebas que cumplan con los requisitos de una explicación científica.

Creo, por tanto, que existe una posibilidad de transformación de la conciencia tanto a nivel individual como colectivo. $\mathrm{Y}$ es importante que ambas transformaciones tengan lugar al mismo tiempo porque la una depende de la otra. Resulta, por tanto, esencial el desarrollo de la capacidad de comunicamos y de la capacidad de dialogar, de la capacidad, en suma, de participar en la comunicación con los demás (Bohm, 1997, pág. 142).

Por lo anteriormente dicho, la actitud comunicativa es en sí misma una mediación pedagógica dado que no busca el consenso o el disenso como mecanismo de cierre del diálogo; sino que permite comprender que en la tensión que se presenta entre el disenso y el consenso es que vamos construyendo diálogos coherentes e incluyentes; donde, desde una perspectiva holística, se reflexiona y comprende el entramado social y se establecen relaciones con la vida 
misma, es allí donde la formación integral comienza a emerger como el desarrollo de todas las dimensiones del ser humano y del universo mismo.

\section{La lectura y la escritura}

Leer es escuchar al autor del texto, teniendo en cuenta que dentro de la categoría texto incluimos todas las expresiones del ser humano que requieren ser decodificadas por el receptor para su comprensión. Por ello, leemos cuando observamos una pintura, leemos las imágenes de una película, leemos los dibujos de un comic, leemos las imágenes de un videojuego, leemos las escenas de la vida cotidiana, leemos entre líneas en una conversación, etc. $Y$ por supuesto leemos textos escritos como los libros, los periódicos, las revistas entre otros muchos. Por ello podemos concluir que a través de la lectura decodificamos los textos y contextos para ampliar nuestro horizonte de sentido, nos apropiamos del lenguaje y formamos nuestro modo de ser y estar en el mundo; es decir, nos apropiamos la cultura.

Quien aprende a leer eficientemente y lo hace con constancia desarrolla, en parte, su pensamiento. Por eso, en definitiva, la lectura se convierte en un aprendizaje transcendental para la escolarización y para el crecimiento intelectual de la persona. Aspectos como el éxito o el fracaso escolar, la preparación técnica para acceder al mundo del trabajo, el grado de autonomía y desenvoltura personales, etc., se relacionan directamente con la capacidad de la lectura. Las expresiones que designan este hecho y que utilizan a menudo en la escuela y en los manuales de pedagogía son: aprender a leer, leer para aprender y aprender a aprender con la lectura (Cassany, Luna, \& Sanz, 1994, pág. 193).

En el proceso de aprendizaje la lectura juega un papel fundamental, pues es la ventana al conocimiento. A través de la lectura se desarrollan las habilidades requeridas para comprender, interpretar, analizar, reflexionar, comparar, inferir, asumir una actitud crítica, etc.; requeridas para desarrollar la capacidad de aprender y comunicar, pues se comunica lo que se ha leído, interpretado, reflexionado, analizado. Pero es necesario aclarar que la lectura va de la mano de la comprensión del significado de las palabras, por lo cual requiere que el lector, en la medida que se enfrenta a conocimientos nuevos, amplíe su léxico para que se comunique de manera clara y coherente.

En el proceso de comunicación se hace presente la escritura, pues para redactar un texto académico se requiere leer para investigar y confrontar nuestras ideas y conceptos con otros 
autores, otras propuestas, otros conceptos y asumir una postura crítica y propositiva frente al tema a tratar. Es allí donde hacemos uso consciente, reflexivo y controlado del conocimiento de la gramática de la lengua para redactar con coherencia y cohesión. Desde esta perspectiva la lectura y la escritura son fundamentales para promover en nuestros estudiantes una actitud comunicativa que les permita establecer diálogos que respondan a las necesidades comunes

del ser humano y del entorno en que vivimos. Si bien la siguiente cita se refiere al mundo de la ingeniería, puede aplicarse a las diversas profesiones:

De ahí que la habilidad para comunicarse sea absolutamente crucial para todo trabajador en la nueva sociedad del conocimiento, y particularmente para el ingeniero. Éste ha de verse a sí mismo como capaz de transmitir la información necesaria a un público muy variado dentro de su propio entorno laboral, desde sus propios colegas en las sociedades profesionales, hasta ese otro público mucho más extenso que es el mundo en general, sobre cuyas vidas recae el impacto de cualquier obra o proyecto de ingeniería. Además, la habilidad para comunicarse de forma clara y precisa es esencial a la habilidad para pensar crítica y creativamente como persona individual o como parte de un grupo. De hecho es difícil, por no decir imposible, intentar abarcar el carácter multidisciplinar de la ingeniería sin buenas destrezas comunicativas (Kindelán \& Martín, 2008, pág. 739).

Son pues la lectura y la escritura mediaciones pedagógicas que permiten que el estudiante ponga en práctica las habilidades propias de la actitud comunicativa para aprender y proyectarse en el mundo de la vida, no como un sujeto aislado y estático; sino como un proyecto en constante construcción, perfectible que se crea y se recrea en el mismo devenir de la vida. $Y$, es en el entramado de las relaciones interiores y con los otros que se van fortaleciendo las dimensiones del ser humano que articulan el desarrollo integral del ser humano.

\section{La comunicación como elemento central de la formación integral}

La cultura occidental ha privilegiado la concepción del hombre como una persona humana íntegra, como totalidad. Por ello la formación integral debe ser un enfoque o forma de educar que enfatice el proceso de constitución de la persona y reconozca todas las dimensiones de ésta que estén presentes en los diversos ámbitos de su existencia individual y social. Desde este enfoque el proceso educativo debe estar centrado en el estudiante, para que, haciendo uso de todas sus potencialidades, constituya y desarrolle su ser personal desde la perspectiva integral de la persona humana. 
La persona humana es un ser social, que sólo en la compañía de sus semejantes encuentra las condiciones necesarias para el desarrollo de su conciencia, racionalidad y libertad. Por lo cual requiere aprender a ejercer esa libertad como disposición habitual, responsable y permanente que le permita obrar racionalmente en relación a los propios deberes y derechos para la búsqueda de su propia realización personal y el bien común de la sociedad. Según la Universidad Santo Tomás, la educación y la formación integral se plantean desde la visión tomista:

\begin{abstract}
En la definición tomista de educación, se relieva el "estado perfecto de hombre en cuanto hombre", es decir, en cuanto ser racional, capaz de auto-dirigir la propia vida y de intervenir como agente de convivencia. Lograr esa madurez racional y esa capacidad auto-directiva que la definición denomina también "estado de virtud"- es, en otras palabras, alcanzar la "formación integral"; que, permeando la formación profesional, potencia el poder unificador de inteligencia, razón y voluntad, y fusiona vida vegetativa, vida sensitiva, vigor físico, sensibilidad, gusto estético, vida emocional, intuición, estimativa, fe, vida espiritual, vida social, vida comunitaria. (USTA, 2004: 63).
\end{abstract}

Para que los valores sean operativos en la educación se requiere que permeen todo su contenido, que sean el espíritu esencial que la ilumina; deben estar presentes en el currículo y ser el fundamento desde el cual se enseñan los conceptos. Para que se vuelvan hábito cultural en los educandos deben ser vividos por los docentes, directivos, padres de familia y sociedad en general. Por ello, se requiere promover la dimensión comunicativa para que le permita encontrar sentido y significado de sí mismo y representarlo a través del lenguaje para interactuar con los demás. El acceso a los valores le permite a la persona comprender que:

$\checkmark$ necesita de los otros y de la cultura para aprender.

$\checkmark$ tiene un valor propio que le permite optar libremente y abrirse a la trascendencia.

$\checkmark$ puede encontrarse consigo mismo y con los demás en el conocimiento y en el amor.

$\checkmark$ puede tener conciencia de sí mismo, de los demás y del mundo.

$\checkmark$ puede hacer uso de su racionalidad y sentimientos, y comportarse con libertad y responsabilidad en la construcción de su proyecto de vida.

Por lo anteriormente dicho, consideramos que la educación en el Siglo XXI deberá proporcionar una formación que permita a los estudiantes desempeñarse como sujetos conscientes de sus derechos y obligaciones, responsables, que utilicen el conocimiento como herramienta para comprender y transformar constructivamente su entorno social, económico, ambiental y cultural, y de situarse como participantes activos en un mundo en permanente 
cambio, para que se vinculen con el mundo del trabajo, la producción, la ciencia y la tecnología desde una perspectiva humanista.

\begin{abstract}
Ahora bien, además de la habilidad para comunicarse, también es necesaria la conciencia de que el aprendizaje de esta y otras destrezas requiere una actitud activa y de responsabilidad del individuo por formarse para estar al día en la adquisición de conocimientos y en el dominio de destrezas requeridos en el mundo de hoy. Por eso, para ser competentes profesionalmente, los trabajadores deben asumir la responsabilidad de su propio aprendizaje siendo conscientes de qué destrezas necesitan aprender o qué actitudes han de adoptar para mejorar su rendimiento y satisfacer las necesidades de la empresa, del cliente y de la sociedad actual (Kindelán \& Martín, 2008, pág. 739).
\end{abstract}

Es por ello que se requiere educar a los jóvenes para que aprendan y asuman su ser libre y ejerzan esa libertad para el perfeccionamiento integral de su propia naturaleza: ser persona humana que se construye y constituye social, cultural e individualmente, a través del aprendizaje y desarrollo pleno de todas sus capacidades intelectuales, morales y físicas, con el objeto de ejercer la libertad con responsabilidad en y desde su subjetividad e intersubjetividad. Pero este proyecto no se agota ni se termina, sino que es un proyecto permanente de autorrealización personal, social y cultural que requiere de desarrollo pleno de la actitud comunicativa para establecer diálogos que responda a las necesidades comunes al ser humano y al entorno en que vivimos. Y, también se requiere que en el proceso de aprendizaje se asuma la lectura y la escritura como mediaciones pedagógicas que promueven la actitud comunicativa, que a su vez potencia el desarrollo de las dimensiones del ser humano que articulan el desarrollo integral del ser humano.

Sin embargo, de todo esto no debe inferirse dogma alguno, sino que deberá representar el triunfo de los conocimientos humanos y de la verdad como un ambicioso cometido en el que están interesadas muchas generaciones y en el cual se dan síntesis, pero no el saber absoluto (Fueter, 1953, pág. 133).

\title{
Referencias
}

Bohm, D. (1997). Sobre el diálogo. Barcelona: Kairós.

Cassany, D., Luna, M., \& Sanz, G. (1994). Enseñar Lengua. Barcelona: Graó.

Fueter, E. (1953). El "Studium Generale" interpretación, Necesidad Evolución (Conclusión). Revista de Educación, 131-136. 
Kindelán, M. P., \& Martín, A. M. (2008). Ingenieeros del Siglo XXI: importnacia de la comunicación y de la formación estratégica en la doble esfera educativa y profesional del ingeniero. ARBOR Ciencia, Pensamiento y Cultura, 731-742.

Maturana, H. (2001). Emociones y lenguaje en educación y política. Chile: Dolmen Ensayo. 